\title{
Treatment of Chronic Suppurative Otitis Media: A Comparison between Topical, Systemic and Combined Topical-Systemic antibiotics
}

\author{
Syed Hasan Imam Al-Masum', Ali Jacob Arsalan²
}

\begin{abstract}
Background and Objectives: The present study was undertaken to determine which of the three treatment modalities (topical, systemic and topical systemic combined) is the best in treating chronic suppurative otitis media (CSOM) in children.

Patients \& Methods: This comparative clinical trial was conducted prospectively in Dhaka Shisu Hospital, Sher-e-Bangla Nagar, Dhaka over a period of 6 months. We enrolled 92 children with chronic CSOM, aged 512 years, from patients attending at pediatric ENT OPD. The children were randomly assigned to three treatment groups. All parents were advised dry mopping of their children two times daily. The first group ( $n$ $=51$ ) received topical ciprofloxacin 4 times daily, the second group received systemic ciprofloxacin only 10 $\mathrm{mg} / \mathrm{kg}$ body weight/day twice daily for 14 days and the third group received both systemic and topical ciprofloxacin. The primary outcome measures were resolution of otorrhoea by $2-3$ weeks of intervention and healing of tympanic membranes on otoscopy by $8-12$ weeks of intervention. Hearing levels were assessed by audiometry.

Results: Of the three groups of children enrolled in the study, the topical-systemic group was significantly older than the topical and systemic groups $(p=0.003)$. However, the groups were not different in terms of sex and duration of illness ( $p=0.125$ and $p=0.191$ respectively). The cardinal presentation was otorrhoea. Over half of the children in each group had marginal perforation $(p=0.062)$. Most of the children in each group had mild hearing impairment $(p=0.212)$. Poor attention and poor academic performance were rarely found. After 2 weeks of treatment, majority of patients in Topical, Systemic and Topical Systemic Combined Group had a successful resolution $(92.1 \%, 95.4 \%$ and $94.7 \%)$ with no significant difference among the groups $(p=0.641)$. Time taken for resolution was almost similar among the groups with mean resolution time being 2 weeks ( $p=0.313$ ). Difference among the groups regarding hearing impairment was evident with highest impairment being in the Topical and the lowest in the combined group $(p=0.048)$. Among groups, topical and systemic group had higher improvement of hearing threshold than topical, systemic combined group $(p=0.024)$. The groups were no different with respect to treatment failure $(p=0.595)$
\end{abstract}

Conclusions: The study concluded that there was no significant difference in outcome in three modalities of treatment - topical, systemic and topical-systemic combined. So only topical antibiotics will do suffice in the treatment of CSOM, unless there is no sign of complications (like fever and/or pain).

Key words: Children, chronic suppurative otitis media (CSOM), Topical and systemic ciprofloxacin.

\section{INTRODUCTION}

Chronic suppurative otitis media (CSOM) is a chronic inflammation of the middle ear and the mastoid process with perforated tympanic membrane and ear discharge persisting for at least two weeks. ${ }^{1}$ CSOM is a common cause of preventable hearing impairment, particularly in low and middle-income countries. It occurs as a complication of acute otitis media, a common condition with an alarming propensity to become chronic in developing countries due to various factors, including inadequate treatment. ${ }^{2}$

\section{Authors' Information:}

${ }^{1}$ Dr. Syed Hasan Imam Al-Masum, Associate Professor, ENT Department, Dhaka Shisu Hospital, Sher-e-Bangla Nagar, Dhaka.

${ }^{2}$ Dr. Ali Jacob Arsalan, Resident Medical Officer, ENT Department, Dhaka Shisu Hospital, Sher-e-Bangla Nagar, Dhaka.

Address of Correspondance: Dr. Syed Hasan Imam Al-Masum, Associate Professor, ENT Department, Dhaka Shisu Hospital, Sher-e-Bangla Nagar, Dhaka. Cell:+880 1711-141543, E-mail: shmasum_ent@yahoo.com 
The incidence of CSOM appears to depend on race, socio-economic factors such as poor living conditions, overcrowding, poor hygiene and nutrition. ${ }^{1}$

In the older child, long standing CSOM can result in a severe conductive hearing loss with significant drawbacks in learning, communication and social adjustment. ${ }^{3}$ Its association with hearing impairment, death and severe disability due to central nervous system involvement, ${ }^{2-6}$ and the high costs incurred in its management makes CSOM a significant health problem in developing countries. The estimate for the combined loss of life from premature death and the loss of healthy life from disability (disabilityadjusted life years) due to CSOM is among the top five common childhood illnesses. ${ }^{7}$ Treatment of children presenting with this condition is often empirical. There is a growing concern over the use of systemic antibiotics and the development of bacterial resistance. Treatment aims to eradicate infection, prevent complications, heal the tympanic membrane, and improve hearing. Treatment options include dry mopping, ear wicking, gentle syringing, or suctioning; systemic antibiotics; and topical treatment with either antiseptics or antibiotics, sometimes with steroids. A Cochrane Review published in $1998^{8}$ concluded that topical treatment with antibiotics or antiseptics is more effective than systemic antibiotics, aural toilet alone, or no treatment at all; and topical quinolones were better than topical non-quinolone antibiotics. Daily instillation of topical antibiotics after meticulous aural toilet for at least 2 weeks appears to be the most cost-effective treatment for the short-term resolution of otorrhoea. Topical quinolones are particularly effective in resolving otorrhoea without the risk of ototoxicity. There is no evidence that the addition of oral antibiotics confers increased benefit. ${ }^{9}$ Despite these data, systemic antibiotics are frequently used in children with CSOM in our country. Sometimes both systemic and topical antibiotics are used together to get additional benefit. To judge the rationality of using systemic antibiotics in CSOM is, therefore, of utmost importance. That purpose of the present study was undertaken to determine the role of systemic antibiotics in CSOM.

\section{Methods \& Materials}

This comparative clinical trial was conducted prospectively in Dhaka Shisu Hospital, Sher-eBangla Nagar, Dhaka over a period of 6 months. We enrolled 92 children with chronic CSOM, aged 5-12 years, from patients attending at pediatric ENT OPD. Children with (a) purulent, aural discharge for 14 days or longer, (b) pus in the external canal and (c) perforation of the tympanic membrane on otoscopy were diagnosed as having CSOM. However, children who had been treated for ear infection or received antibiotics for any other disorder in the previous 2 weeks, or who had other ear problems (preexisting disease, complicated otitis media, anatomical abnormalities) or allergy to study drugs were excluded from the study. Presence of tympanostomy tube or known hepatitis or acute or chronic renal failure also prevent children from participating in the study. The children were randomly assigned to three treatment groups. All parents were advised dry mopping of their children two times daily. The first group $(n=51)$ received topical ciprofloxacin 4 times daily, the second group received systemic ciprofloxacin only $(\mathrm{n}=22) 10 \mathrm{mg} / \mathrm{kg}$ body weight/day twice daily for 14 days and the third group received both systemic and topical ciprofloxacin ( $n=19)$. The primary outcome measures were resolution of otorrhoea by 2 - 3 weeks of intervention and healing of tympanic membranes on otoscopy by $8-12$ weeks of intervention. Hearing levels were assessed by audiometry. Statistical analyses were performed using descriptive statistics, Chisquare and ANOVA statistics. The level of significance was set at 0.05 and $p<0.05$ was considered significant.

\section{RESULT}

\section{Demographic characteristics:}

Of the three groups of children enrolled in the 
older than the topical and systemic groups ( $\mathrm{p}=$ $0.003)$. However, there was no significant difference among the groups with respect to sex ( $p=0.125$ ). The topical group had a significantly higher proportion poor children than the other two groups $(p=0.020)$. The duration of suffering from the disease was almost similar among the three groups of children ( $p=0.191$ ) (Table I).

\begin{tabular}{|c|c|c|c|c|}
\hline $\begin{array}{l}\text { Demographic } \\
\text { characteristics }\end{array}$ & $\begin{array}{l}\text { Topical } \\
(n=51)\end{array}$ & $\begin{array}{r}\text { Grou } \\
\text { Systemic } T \\
(n=22)\end{array}$ & $\begin{array}{l}\text { up } \\
\text { Topical-Systemic Combined } \\
\qquad(n=19)\end{array}$ & p-value \\
\hline Age $(y r s)^{\#}$ & $6.1 \pm 2.7$ & $5.9 \pm 2.3$ & $8.4 \pm 2.5$ & 0.003 \\
\hline \multicolumn{5}{|l|}{ Sex ${ }^{*}$} \\
\hline Male & $24(47.1)$ & $16(72.7)$ & $11(57.9)$ & 0.125 \\
\hline Female & $27(52.9)$ & $6(27.3)$ & $8(42.1)$ & \\
\hline \multicolumn{5}{|c|}{ Socioeconomic status ${ }^{*}$} \\
\hline Poor & $32(62.7)$ & $6(27.3)$ & $9(47.4)$ & 0.020 \\
\hline Middle class & $19(37.3)$ & $16(72.7)$ & $10(52.6)$ & \\
\hline Duration of $\mathrm{CSOM}^{\#}$ & $2.0 \pm 0.3$ & $2.0 \pm 0.0$ & $2.0 \pm 0.0$ & 0.191 \\
\hline
\end{tabular}

\section{Involved ear:}

In terms of involvement of ears, the left ears were affected a little more than the right ears in all the three groups. A few patients in all the groups, however, had both ear involvements (Fig. 1). There was no significant difference among the groups with respect to involvement of ears.

\section{Clinical presentation:}

Almost all the patients of the three groups showed otorrhoea as a symptom ( $p=0.666)$. Though, more than $50 \%$ patients in each group had marginal perforation, the difference among the groups was not significant enough (0.062). There was no significant difference among the groups in terms of hearing impairment $(p=$ 0.212). Distribution of children among the study groups with respect to severity of hearing impairment was almost identical ( $p=0.531$ ). Poor attention and poor academic performance were rarely found (Table II).

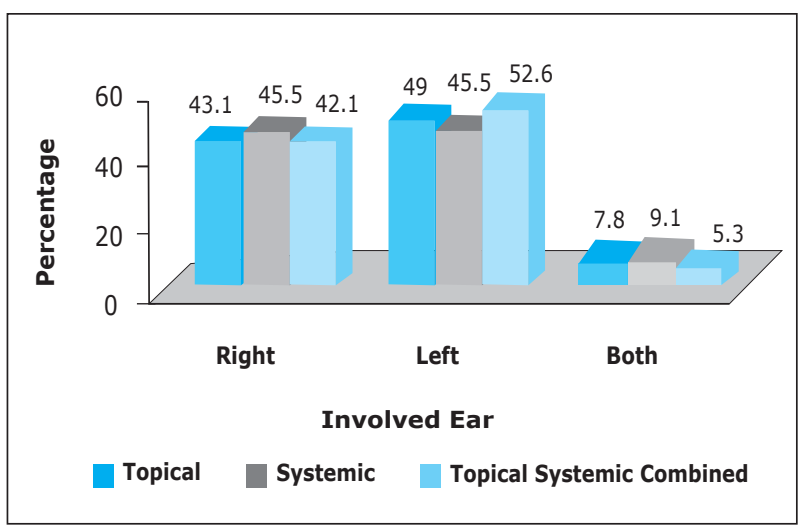

FIGURE 1: Comparison of involved ear between groups $(n=92)$

\begin{tabular}{|c|c|c|c|c|}
\hline $\begin{array}{l}\text { Presenting } \\
\text { complaints }\end{array}$ & $\begin{array}{l}\text { Topical } \\
(n=51)\end{array}$ & $\begin{array}{l}\text { Group } \\
\text { Systemic T } \\
(n=22)\end{array}$ & $\begin{array}{l}\text { Topical-Systemic Combined } \\
\qquad(n=19)\end{array}$ & $p$-value \\
\hline Otorrhoea* & $50(98.0)$ & $22(100.0)$ & $19(100.0)$ & 0.666 \\
\hline \multicolumn{5}{|c|}{ Size of perforation* } \\
\hline Marginal & $34(66.7)$ & $19(86.4)$ & $10(52.6)$ & 0.062 \\
\hline Subtotal & $17(33.3)$ & $3(13.6)$ & $9(47.4)$ & \\
\hline $\begin{array}{l}\text { Hearing } \\
\text { impairment (dB) }\end{array}$ & $21.4 \pm 3.6$ & $20.9 \pm 1.9$ & $20.2 \pm 1.1$ & 0.212 \\
\hline \multicolumn{5}{|c|}{ Hearing Impairment* } \\
\hline Mild & $40(78.4)$ & $17(77.2)$ & $15(78.9)$ & 0.531 \\
\hline Moderate & $11(21.6)$ & $5(22.8)$ & $4(21.1)$ & \\
\hline Poor attention* & $8(15.7)$ & $0(0.0)$ & $0(0.0)$ & 0.030 \\
\hline $\begin{array}{l}\text { Poor academic } \\
\text { performance* }\end{array}$ & $5(9.8)$ & $0(0.0)$ & $0(0.0)$ & 0.119 \\
\hline
\end{tabular}

Figures in the parentheses indicate corresponding \%; *Chi-squared Test $\left(\mathrm{c}^{2}\right)$ was done to analyze the data.

\#Data were analyzed using Oneway ANOVA and were presented as mean \pm SD.

\section{Outcome:}

After 2 weeks of treatment, majority of patients in Topical, Systemic and Topical Systemic combined group had a successful resolution $(92.1 \%, 95.4 \%$ and $94.7 \%)$ with no significant 
difference among the groups $(p=0.641)$. Time taken for resolution was almost similar among the groups with mean resolution time being 2 weeks $(p=0.313)$. More than $60 \%$ of the patients in the Topical group $72.7 \%$ in systemic group had marginal perforation unlike the combined group where more patients (68\%) had subtotal perforation ( $p=0.023$ ). Difference among the groups regarding hearing impairment was evident with highest impairment being in Topical and the lowest in the combined group $(p=0.048)$. Among groups, topical and systemic group had higher improvement of hearing threshold than topical-systemic combined group $(p=0.024)$. The groups were no different with respect to treatment failure $(p=0.595)$ (Table III).

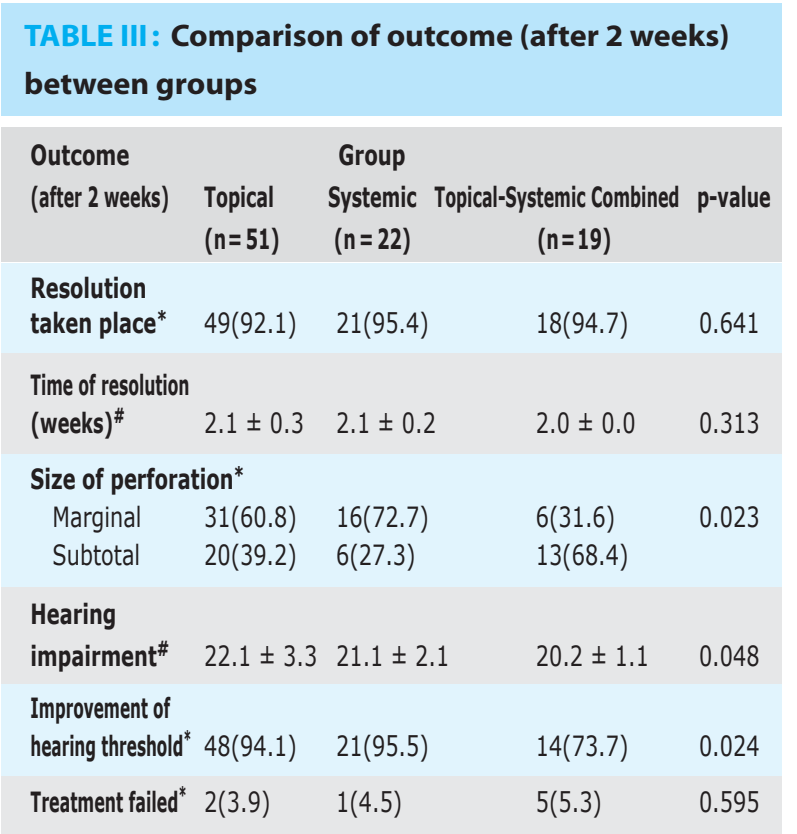

Figures in the parentheses indicate corresponding \%; *Chi-squared Test $\left(\mathrm{c}^{2}\right)$ was done to analyze the data.

\#Data were analyzed using Oneway ANOVA and were presented as mean $\pm S D$.

\section{Discussion}

Chronic suppurative otitis media (CSOM) is a commonly encountered infection of the middle ear all over the world. Untreated cases of CSOM can result in a broad range of complications. These may be related to the spread of bacteria to structures adjacent to the ear or to local damage in the middle ear itself. Such complications range from persistent otorrhoea, mastoiditis, labyrinthitis, facial nerve paralysis to more serious intracranial abscesses or thromboses. ${ }^{10-12}$ So the knowledge of the right treatment of infection is essential to enable clinicians for rationale use of antibiotics to this disorder.

The present study demonstrated that the cardinal presentation of children with CSOM was otorrhoea followed by marginal perforation and mild hearing impairment. Poor attention and poor academic performance were rarely found. After 2 weeks of treatment, most of the patients in Topical, Systemic and Topical Systemic combined groups had a successful resolution (92.1\%, $95.4 \%$ and $94.7 \%$ ) with no significant difference among the groups ( $p=0.641)$. Time taken for resolution was almost similar among the groups with mean resolution time being 2 weeks ( $p=$ $0.313)$. More than $60 \%$ of the patients in the Topical group, $72.7 \%$ in systemic group had marginal perforation unlike the combined group where more patients $(68 \%)$ had subtotal perforation ( $p=0.023$ ). The highest hearing impairment was evident in Topical and the lowest in the combined group $(p=0.048)$. Among groups, topical and systemic group had higher improvement of hearing threshold than topicalsystemic combined group $(p=0.024)$. The treatment failure was rare with no significant difference among the groups $(p=0.595)$.

The three relevant articles: the WHO guidelines of 2004,13 the Cochrane review of topical versus systemic antibiotics of $2006^{14}$ and the systematic review of topical versus systemic antibiotics for CSOM conducted in children ${ }^{15}$ and the evidence on topical versus systemic antibiotics taken from six other studies favoured topical antibiotics for resolving otorrohea and eradicating middle ear bacteria. The Cochrane review concluded that of the topical antibiotics studied, topical quinolones were more effective than topical nonquinolones, and that there was no additive benefit from combining systemic and topical antibiotics. ${ }^{16}$ The guideline authors also note that "there is general 
agreement that aural toilet must be part of the standard medical treatment for CSOM",17 because it reduces the quantity of infected material, thereby facilitating penetration of topical treatments. The 2006 Cochrane review on topical treatments (excluding steroids) versus systemic antibiotics included nine trials, all involving adults, although four also included children. No subgroup analysis according to age was performed. This review found topical quinolone to be more effective over systemic nonquinolones. They also performed an analysis of systemic quinolone plus topical quinolone antibiotics versus systemic quinolone antibiotics alone, finding an effect in favour of the combination.

The benefits of exclusively analyzing paediatric data motivated Woodfield and Dugdale ${ }^{15}$ to rerun the searches from the Cochrane reviews, selecting only the trials involving children. None of these directly compared topical with systemic antibiotics. Nonetheless, they concluded that topical quinolones alone were the most effective short-term treatment for CSOM in children bearing consistency with findings of the present study. There are some theoretical reasons for the superiority of topical over systemic administration of antibiotics for CSOM. Due to poor vascularization of the middle ear mucosa, systemically delivered antibiotics do not penetrate well. For example, oral amoxicillin at $90 \mathrm{mg} / \mathrm{kg}$ results in a middle ear concentration of only $6 \mathrm{mg} / \mathrm{mL}$ to $10 \mathrm{mg} / \mathrm{mL}$ compared with $3000 \mathrm{mg} / \mathrm{mL}$ of antibiotic following application of a $0.3 \%$ antibiotic solution of ciprofloxacin. Another advantage of topical administration is the decrease in side effects due to limited systemic absorption. ${ }^{18}$ Thus, the evidence presented here and the findings of the present study support the use of topical quinolone antibiotics in conjunction with aural toilet for short-term resolution of otorrhea from uncomplicated CSOM.

Literature on CSOM therapy primarily uses the short-term clearance of ear drainage as the primary outcome. The literatures convincingly show that topical antibiotics are superior to antiseptic drops, or no treatment, in shortening the duration of ear drainage. ${ }^{19}$ While the literature on CSOM has shortcomings with respect to the length of follow-up, sample size, methodological quality and the lack of paediatric studies, there is reasonable evidence for the efficacy of topical quinolones following aural toilet. Because the most common pathogen is Pseudomonas aeruginosa, 20-22 followed by other aerobic bacteria, such as Staphylococcus aureus and Gram-negative organisms and, to a lesser degree, anaerobic pathogens, it makes sense that quinolones would work better than nonquinolones.

The topical quinolones have a better safety profile than other agents. ${ }^{18}$ In a recent report from the American Academy of Pediatrics, ${ }^{23}$ although CSOM was not specifically addressed, quinolone-containing preparations were reported to represent a safer alternative for treating both otorrhoea associated with tympanic membrane perforation and tympanostomy tube otorrhoea than were aminoglycoside-containing otic preparations. The most commonly reported and important long-term sequelae of CSOM are permanent tympanic membrane damage and hearing loss. ${ }^{17}$ These may affect a young child's language development and school progress. Although decreasing the number of days of ear drainage will be appreciated by children and their parents, it is not clear whether this will have any effect on long-term hearing because no high quality studies have long-term follow-up with regard to hearing.

\section{Conclusion}

The study concluded that there was no significant difference in outcome in three modalities of treatment topical, systemic and topical-systemic combined. So only topical antibiotics will do suffice in the treatment of CSOM, unless there is no sign of complications (like fever and/or pain). 


\section{REFERENCES}

1. Jahn AF. Chronic otitis media: diagnosis and treatment. Med Clin North Am 1991;75(6):1277-91.

2. McPherson B, Holborow CA. A study of deafness in West Africa: the Gambian hearing health project. Int J Pediatr Otorhinolaryngol 1985;10:115-35.

3. Tos M. Sequelae of secretory otitis media and the relationship to chronic suppurative otitis media. Ann Otol Rhino Laryngol 1990;99(4)(Suppl. 146):18-9.

4. McPherson B, Holborow CA. A study of deafness in West Africa: the Gambian hearing health project.Int J Pediatr Otorhinolaryngol 1985;10:115-135.

5. Daly KA, Hunter LL, Levine SC, Lindgren BR, Giebink GS. Relationships between otitis media sequelae and age. Laryngoscope 1998;108(9):1306-10.

6. Tos M. Causes of the disease. Ann Otolaryngol Head Neck Surg 1990;99(4) (Suppl. 146):7.

7. Mahoney JL. Mass management of otitis media in Zaire. Laryngoscope 1980;90(7, Pt 1):1200-1208.

8. Acuin J, Smith A, Mackenzie I. Interventions for chronic suppurative otitis media (Cochrane Review). In: The Cochrane Library, Issue 2. UK: John Wiley \& Sons Ltd, Chichester. 2004.

9. Chronic suppurative Otitis Media: Burden of Illness and Management Options. Child and Adolescent Health and Development, Prevention of Blindness and Deafness, World Health Organization, Geneva. 2004; p. 7-8.

10. Healy, GB, Rosbe, KW. Otitis media and Middle Ear Effusions. In: Snow JB, Ballenger JJ, editors. Ballenger's Otorhinolaryngology Head and Neck Surgery, $16^{\text {th }}$ ed. Hamilton, Ontario, Canada: BC Decker Inc.; 2003. p. 249-60.

11. Loy AHC, Tan AL, Lu PKS. Microbiology of chronic supurative otitis media in Singapore. Singapore Med J 2002;43(6):296-99.

12. Sweeney G, Piccozi GL, Browning GG. A quantitative study of aerobic and anaerobic bacteria in chronic suppurative otitis media. J Infect 1982;5:47-55.

13. World Health Organization. Chronic suppurative otitis media: Burden of illness and management options. Geneva, Switzerland.2004. [cited 2014 Jan 17]; P 32-43. Available from: http://apps.who.int/iris/handle/ 10665/42941
14. Macfadyen CA, Acuin JM, Gamble C. Systemic antibiotics versus topical treatments for chronically discharging ears with underlying eardrum perforations. Cochrane Database of Syst Rev 2006;1:CD005608.

15. Woodfield G, Dugdale A. Clinical review: Evidence behind the WHO guidelines: Hospital care for children: What is the most effective antibiotic regime for chronic suppurative otitis media in children? J Trop Pediatr 2008; $54: 151-6$.

16. Acuin JM, Smith A, Mackenzie I. Interventions for chronic suppurative otitis media. Cochrane Database of Syst Rev 1998;4:CD000473.

17. Verhoeff M, van der Veen EL, Rovers MM, Sanders EAM, Schilder AGM. Chronic suppurative otitis media: A review. Int J Pediatr Otorhinolaryngol 2006;70:1-12.

18. Daniel SJ. Topical treatment of chronic suppurative otitis media. Curr Infect Dis Rep 2012;14:121-7.

19. Macfadyen CA, Acuin JM, Gamble C. Topical antibiotics without steroids for chronically discharging ears with underlying eardrum perforations. Cochrane Database of Syst Rev 2005;4:CD004618.

20. Couzos S, Lea T, Mueller R, Murray R, Culbong $M$. Effectiveness of ototopical antibiotics for chronic suppurative otitis media in Aboriginal children: A community-based, multicentre, double-blind randomised controlled trial. Med J Aust 2003; 179:185-90.

21. Papastavros T, Giamarellou H, Varlejides S. Role of aerobic and anaerobic microorganisms in chronic suppurative otitis media. Laryngoscope 1986;96: 438-42.

22. Erkan M, Aslan T, Sevük E, Güney E. Bacteriology of chronic suppurative otitis media. Ann Otol Rhinol Laryngol 1994;103:771-4.

23. Bradley JS, Jackson M. American Academy of Pediatrics, Committee on Infectious Diseases. The use of systemic and topical fluoroquinolones. Pediatrics 2011;128: e1034-45. 